ARTICLE

\title{
Geminiviruses employ host DNA glycosylases to subvert DNA methylation-mediated defense
}

Xiaojian Gui ${ }^{1,2}$, Chang Liu ${ }^{3,4}$, Yijun Qi (ib) ${ }^{3,4 凶}$ \& Xueping Zhou (i) ${ }^{1,2 凶}$

DNA methylation is an epigenetic mechanism that plays important roles in gene regulation and transposon silencing. Active DNA demethylation has evolved to counterbalance DNA methylation at many endogenous loci. Here, we report that active DNA demethylation also targets viral DNAs, tomato yellow leaf curl China virus (TYLCCNV) and its satellite tomato yellow leaf curl China betasatellite (TYLCCNB), to promote their virulence. We demonstrate that the $\beta C 1$ protein, encoded by TYLCCNB, interacts with a ROS1-like DNA glycosylase in Nicotiana benthamiana and with the DEMETER (DME) DNA glycosylase in Arabidopsis thaliana. The interaction between $\beta C 1$ and DME facilitates the DNA glycosylase activity to decrease viral DNA methylation and promote viral virulence. These findings reveal that active DNA demethylation can be regulated by a viral protein to subvert DNA methylationmediated defense.

\footnotetext{
${ }^{1}$ State Key Laboratory of Rice Biology, Institute of Biotechnology, Zhejiang University, Hangzhou 310058, China. ${ }^{2}$ State Key Laboratory for Biology of Plant Diseases and Insect Pests, Institute of Plant Protection, Chinese Academy of Agricultural Sciences, Beijing 100193, China. ${ }^{3}$ Center for Plant Biology, School of Life Sciences, Tsinghua University, Beijing 100084, China. ${ }^{4}$ Tsinghua University-Peking University Joint Center for Life Sciences, School of Life Sciences,

Tsinghua University, Beijing 100084, China. ${ }^{凶}$ email: qiyijun@tsinghua.edu.cn; zzhou@zju.edu.cn
} 
C ytosine DNA methylation plays important roles in transposon silencing and gene regulation ${ }^{1}$. In plants, DNA methylation occurs in $\mathrm{CG}, \mathrm{CHG}$, and $\mathrm{CHH}$ (where $\mathrm{H}$ represents $\mathrm{A}$, $\mathrm{T}$, or $\mathrm{C}$ ) sequence contexts ${ }^{2-4}$. CG, $\mathrm{CHG}$, and $\mathrm{CHH}$ methylation are established by Domains Rearranged Methyltransferase 2 through the RNA-directed DNA methylation (RdDM) pathway ${ }^{5}$ and maintained by different mechanisms. CG and CHG methylation are maintained by METHYLTRANSFERASE $1^{6}$ and CHROMOMETHYLASE $3^{7}$, respectively, whereas $\mathrm{CHH}$ methylation is maintained by CMT2 and $\mathrm{RdDM}^{8}$. All DNA methylation reactions use $S$-adenosyl-L-methionine (SAM) as the donor of methyl groups ${ }^{9}$.

DNA methylation can be passively or actively removed, and the balance between methylation and demethylation determines the final methylation pattern ${ }^{1}$. In Arabidopsis, active DNA demethylation involves the removal of 5-methylcytosine $(5 \mathrm{mC})$ by the DME family of DNA glycosylases, which include REPRESSOR OF SILENCING 1 $(\mathrm{ROS} 1)^{10}$, DEMETER (DME) $)^{11}$, DEMETER-LIKE PROTEIN 2 (DML2), and DML $3^{12}$. ROS1, DML2, and DML3 are expressed in vegetative tissues, whereas DME is preferentially expressed in the gametes $^{11,13}$. ROS1, DML2, and DML3 target thousands of endogenous loci ${ }^{2,4,14}$ and are important for the development of xylem tracheary elements and leaf stomatal cells ${ }^{15,16}$. DME targets thousands of endogenous loci in vegetative cells, the companion cells of sperms ${ }^{17}$, and initiates genome-wide active DNA demethylation in central cells, the companion cells of egg cells ${ }^{18}$, thereby regulating pollen germination ${ }^{13}$ and embryo development ${ }^{11}$.

Plant viruses infect a wide range of plant species and cause devastating crop losses all over the world. The family Geminiviridae comprises circular single-stranded DNA viruses. This family is currently divided into 14 genera on the basis of their genome organization, insect vector, and host range, with the genus Begomovirus being the largest ${ }^{19}$. The begomovirus tomato yellow leaf curl China virus (TYLCCNV), which can infect Nicotiana benthamiana, is associated with a betasatellite DNA (TYLCCNB) ${ }^{20}$. TYLCCNB encodes $\beta C 1$, which determines the pathogenicity of TYLCCNV $^{20}$. The multifunctional protein $\beta \mathrm{C} 1$ can block MitogenActivated Protein Kinase signaling 21 , interfere with posttranscriptional and transcriptional gene silencing 22,23 and manipulate jasmonic acid signaling ${ }^{24-26}$ to subvert host defense.

DNA methylation can act as a defense mechanism against DNA viruses, including geminiviruses. Viral genomic DNA can be methylated $^{27-29}$, and therefore its replication is suppressed ${ }^{30,31}$. To counteract this inhibition, viruses encode suppressor proteins to interfere with DNA methylation ${ }^{32-36}$ or the production of $\mathrm{SAM}^{22,37-39}$. It has been shown that $\beta \mathrm{C} 1$ can interact with and inactivate $S$-adenosyl homocysteine hydrolase $(\mathrm{SAHH})$, an enzyme needed for SAM production, to suppress DNA methylation and enhance TYLCCNV virulence ${ }^{22}$. Thus far, whether active DNA demethylation plays a role in plant-virus interactions and whether the active DNA demethylation machinery is targeted by virus-encoded proteins remain unknown.

In this study, we investigated the role of active DNA demethylation in plant-virus interactions. We used TYLCCNV and its betasatellite TYLCCNB as a model system ${ }^{20}$. We found that active DNA demethylation promotes viral DNA hypomethylation and TYLCCNV/TYLCCNB virulence. $\beta C 1$ interacts with $\mathrm{NbROS} 1 \mathrm{~L}$ in Nicotiana benthamiana and with DME in Arabidopsis. The interaction between $\beta \mathrm{C} 1$ and DME enhances the DNA glycosylase activity to counteract viral DNA methylation and increase viral virulence.

\section{Results}

Active DNA demethylation promotes viral DNA hypomethylation and TYLCCNV/TYLCCNB virulence in $N$. benthamiana. By searching for ROS1 orthologs, we identified six DME-like (DML) DNA glycosylases in N. benthamiana, namely NbROS1,
NbROS1L, NbDML3, NbDML4, NbDML5 and NbDML6 (Supplementary Fig. 1a). Except $N b D M L 6$, they appeared to be ubiquitously expressed in N. benthamiana plants (Supplementary Fig. 1b). We tested their role in the plant-virus interactions by knocking down their expression by using tobacco rattle virus (TRV)-induced gene silencing (VIGS) (Supplementary Figs. 2 and 3a). Plants infiltrated with pCambia1300 (TRV-free empty vector), with TRV-GUS (as a VIGS control) and with TRV-NbDMLs were mock-inoculated, inoculated with TYLCCNV alone, or inoculated with TYLCCNV plus TYLCCNB (TYLCCNV+B). pCambia1300-, TRV-GUS- or TRV-NbDMLs-infiltrated plants did not show any symptoms when inoculated with TYLCCNV alone (Fig. 1a and Supplementary Fig. 3b), consistent with the previous finding that TYLCCNV alone does not induce disease symptoms in $N$. benthamiana ${ }^{20}$. When inoculated with TYLCCNV+B, pCambia1300- and TRV-GUS-infiltrated plants showed dramatically curled leaves, whereas plants infiltrated with TRV-NbDMLs displayed only mild symptoms (Fig. 1a and Supplementary Fig. 3b). We next performed Southern blot and quantitative PCR (qRCR) analyses to determine the accumulation of viral DNA in infected leaves. Comparably low levels of TYLCCNV DNA accumulated in pCambia1300-, TRV-GUSor TRV-NbDMLs-infiltrated plants when inoculated with TYLCCNV alone. High levels of TYLCCNV and TYLCCNB were accumulated in plants infiltrated with pCambia1300- or TRVGUS then inoculated with TYLCCNV+B. However, the viral load was significantly decreased in plants infiltrated with TRVNbDMLs (Fig. 1b, c and Supplementary Fig. 3c). These results validate that TYLCCNB promotes TYLCCNV infection ${ }^{20}$, and suggest that active DNA demethylation plays a major role in the promotion of TYLCCNV infection by TYLCCNB.

Given that active DNA demethylation counteracts DNA methylation, we wondered whether removal of DNA methylation from viral genome is associated with the high accumulation of TYLCCNV/ TYLCCNB and increased symptom severity. To test this, we performed bisulfite sequencing to measure the methylation levels of TYLCCNV genomic DNA, represented by an intergenic region that contains the origin of replication and divergent viral promoters (Supplementary Fig. 3d). We found that $23 \%$ C's in TYLCCNV were methylated in plants inoculated with TYLCCNV alone, regardless of whether NbDMLs were knocked down (Fig. 1d). The levels of methylation decreased to $\sim 12 \%$ in plants infiltrated with pCambia1300 or TRV-GUS then inoculated with TYLCCNV+B. Knockdown of $N b D M L$ s greatly restored methylation of the viral DNA (Fig. 1d). These results suggest that TYLCCNB causes a decrease in viral DNA methylation, which is mainly achieved through active DNA demethylation.

$\beta C 1$ interacts with NbROS1L. $\beta \mathrm{C} 1$ can suppress DNA methylation through inactivating $\mathrm{SAHH}^{22}$. Given our finding that the TYLCCNB-mediated decrease in viral DNA methylation is mainly dependent on $N b D M L$ s, we reasoned that $\beta C 1$ could also target the active DNA demethylation machinery. The expression levels of $N b D M L s$ were not significantly different in mock-, TYLCCNV - or TYLCCNV+B-inoculated plants (Supplementary Fig. 4a), suggesting that $\beta \mathrm{C} 1$ does not transcriptionally regulate NbDMLs. We then tested whether $\beta \mathrm{C} 1$ can interact with NbDMLs by performing bimolecular fluorescence complementation (BiFC) assays. We found that $\beta \mathrm{C} 1$ could interact with NbROS1L in the nucleus, but not with other members of the family (Fig. 2a and Supplementary Fig. 4b, c). Further analyses revealed that the $\mathrm{N}$-terminal region of NbROS1L mediated its interaction with $\beta \mathrm{C} 1$ (Fig. $2 \mathrm{~b}$ and Supplementary Fig. $4 \mathrm{~d}$ ). The interaction between $\beta \mathrm{C} 1$ and the $\mathrm{N}$-terminal region of NbROS1L was confirmed by co-immunoprecipitation (Fig. 2c). We then 
a
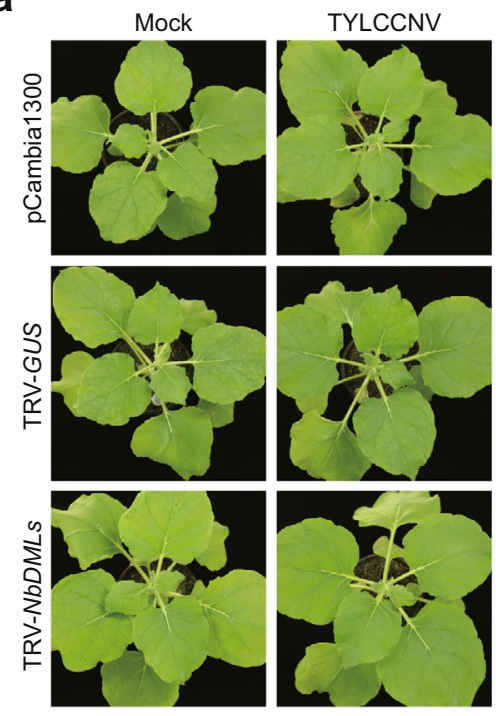

C

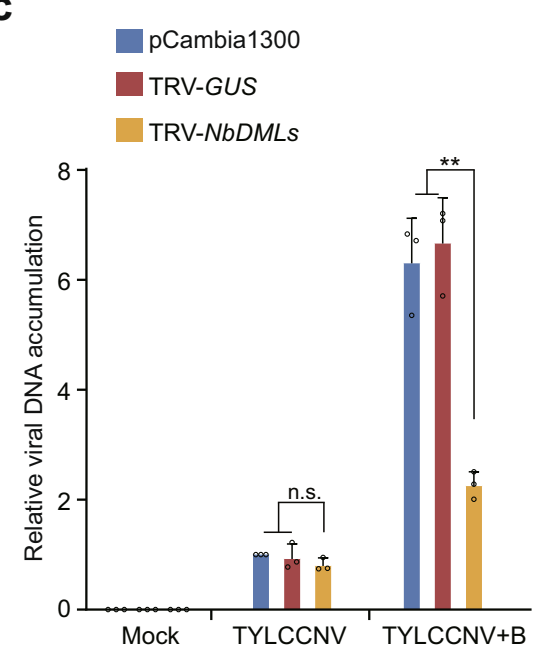

TYLCCNV
TYLCCNV+B

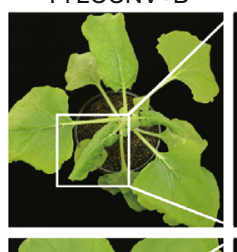

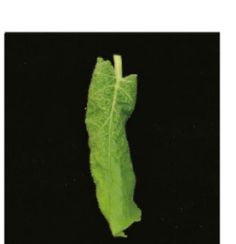

b
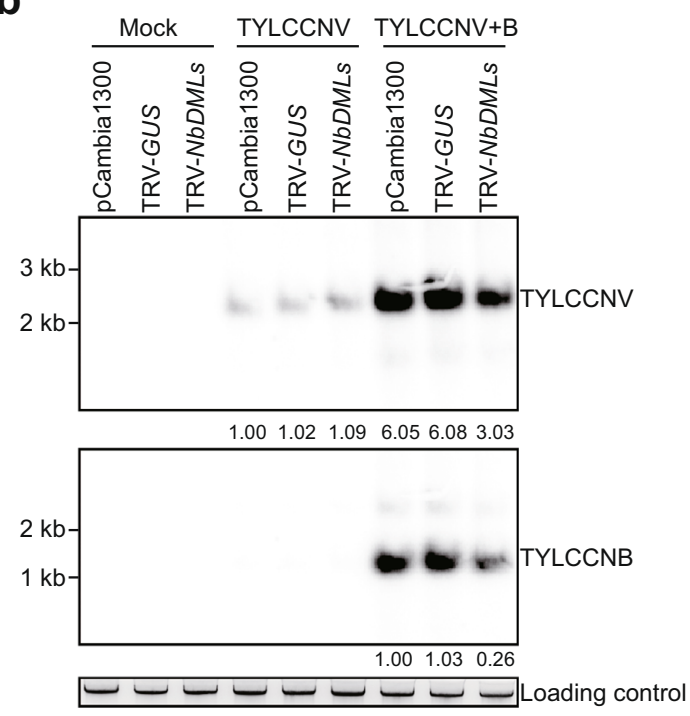

d

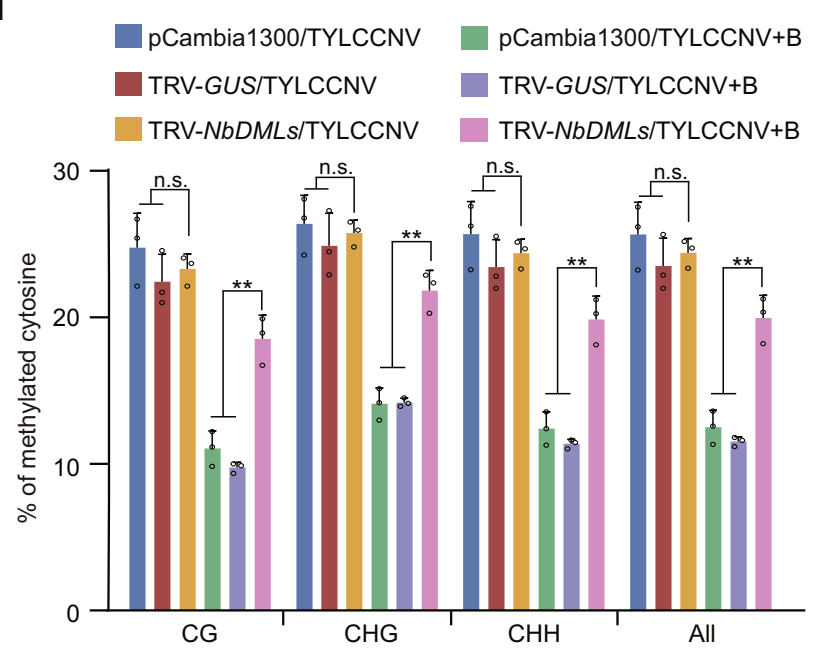

Fig. 1 Active DNA demethylation promotes TYLCCNV+B virulence and viral DNA hypomethylation in N. benthamiana. a Symptoms of $p C a m b i a 1300-$, TRV-GUS-, and TRV-NbDMLs-infiltrated N. benthamiana plants mock-inoculated, or inoculated with TYLCCNV or TYLCCNV+B. Photographs were taken at 10 days post inoculation (dpi). Scale bar, $2 \mathrm{~cm}$. b Accumulation of TYLCCNV and TYLCCNB in the leaves of indicated plants at 10 dpi as determined by Southern blot. Total DNA was stained with ethidium bromide (EB) as loading control. c Accumulation of TYLCCNV in the leaves of indicated plants at 10 dpi as determined by GPCR. The coat protein gene of TYLCCNV was amplified. The N. benthamiana 255 nuclear rRNA gene (Nb25SrRNA) was used as an internal control. Values are means \pm SD $\left(n=3\right.$ independent experiments). Statistical significance was determined using two-tailed Student's $t$ test; ${ }^{* \star} p<0.01$, ns not significant. d Percentage of methylated cytosines in the intergenic region (IR) of TYLCCNV in the leaves of indicated plants as determined by bisulfite sequencing. Values are means \pm SD ( $n=3$ independent experiments). Statistical significance was determined using two-tailed Student's $t$ test; ${ }^{* \star} p<0.01$, ns not significant. Uncropped pictures, blots and gels for $\mathbf{a}$ and $\mathbf{b}$, raw data and $p$ values for $\mathbf{c}$ and $\mathbf{d}$ are provided in the source data.

mapped the region of $\beta C 1$ that is required for its interaction with NbROS1L, and identified a 10-amino acid motif, from residue 11 to 20, essential for the interaction (Supplementary Fig. 5a, b). Further mutational analysis showed that replacement of the Val in position 17 of $\beta \mathrm{C} 1$ with $\mathrm{Ala}(\mathrm{V} 17 \mathrm{~A})$ abolished the interaction with NbROS1L (Fig. 2d, e and Supplementary Fig. 5c), but did not affect its interaction with SAHH (Supplementary Fig. 5d, e), indicating that V17 is specifically required for the interaction between $\beta \mathrm{C} 1$ and NbROS1L (Fig. 2d, e).

The $\beta C 1-N b R O S 1 L$ interaction is important for TYLCCNV $+B$ virulence and viral DNA hypomethylation. We next investigated whether the $\beta \mathrm{C} 1-\mathrm{NbROS} 1 \mathrm{~L}$ interaction is important for the TYLCCNB-mediated methylation decrease and promotion of virulence. For this purpose, we generated a TYLCCNB clone expressing $\beta \mathrm{C} 1 \mathrm{~V} 17 \mathrm{~A}$. Interestingly, plants inoculated with TYLCCNV $+\mathrm{B}^{\mathrm{V} 17 \mathrm{~A}}$ showed very mild symptoms and lower levels of TYLCCNV/TYLCCNB accumulation (Fig. 3a-c and Supplementary Fig. 6a, b); concomitantly, higher levels of viral DNA methylation were detected (Fig. 3d). These results suggest that the interaction between $\beta C 1$ and $\mathrm{NbROS} 1 \mathrm{~L}$ is important for the TYLCCNB-mediated decrease in viral DNA methylation and TYLCCNV/TYLCCNB virulence.

The $\beta C 1-D M E$ interaction promotes BSCTV virulence and viral DNA hypomethylation in Arabidopsis. To examine whether the role of $\beta C 1$ in regulating active DNA demethylation and viral infection is conserved in other plant species, we tested 
a

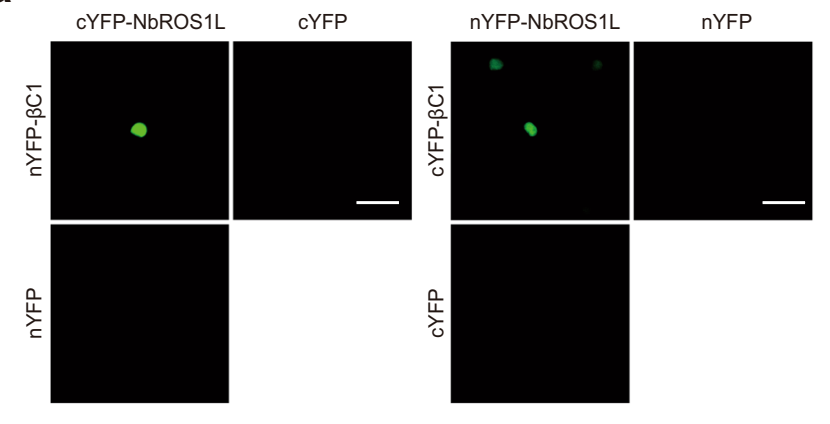

C

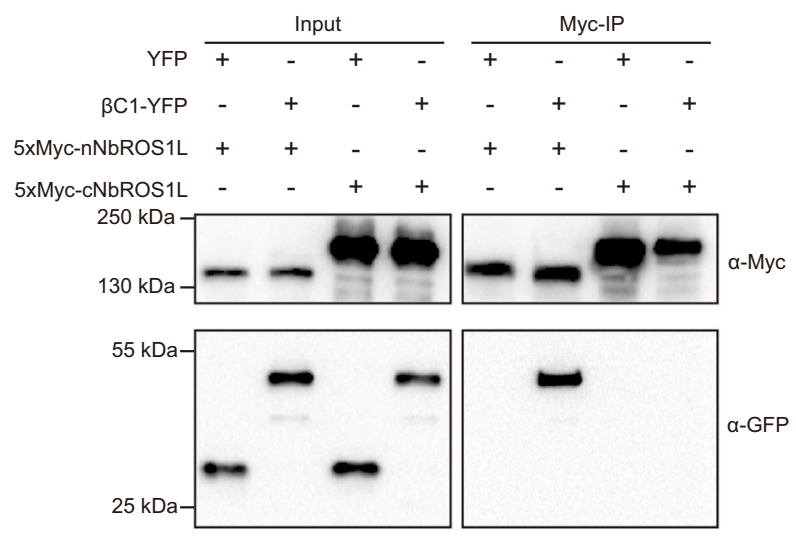

b
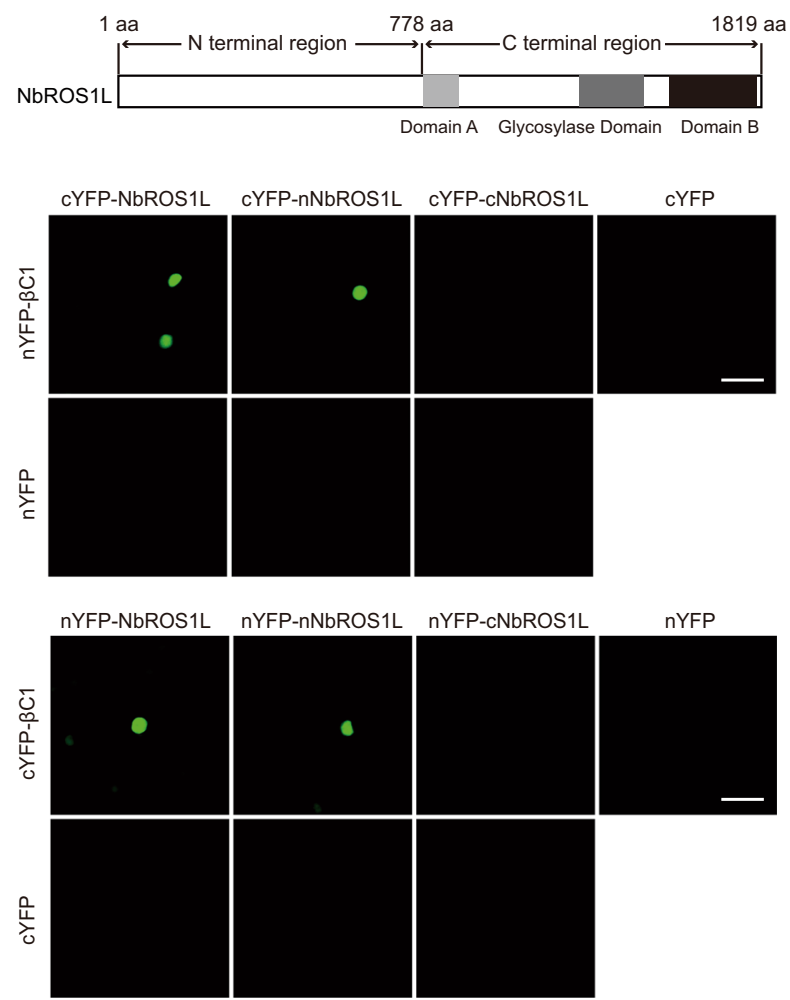

d

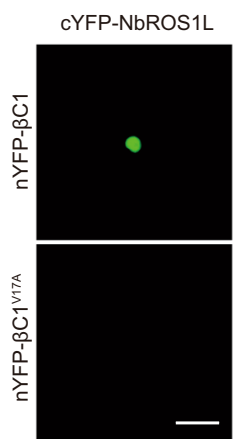

nYFP-NbROS1L

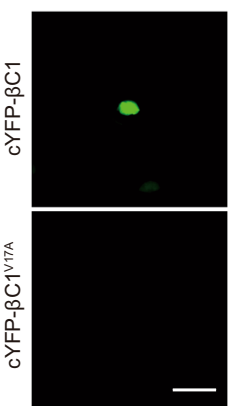

e

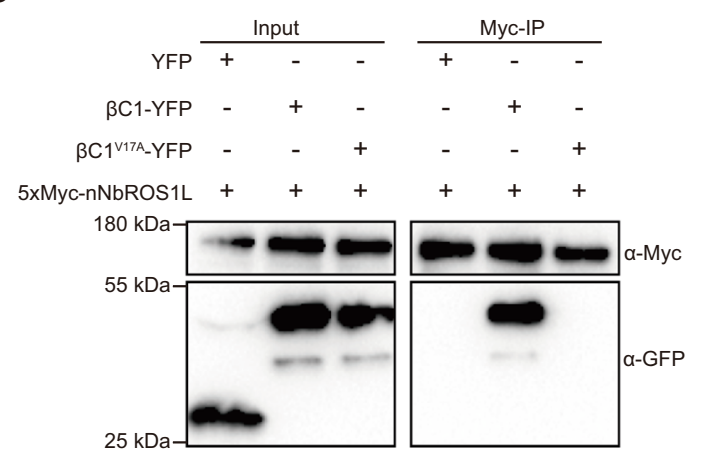

Fig. $2 \boldsymbol{\beta C 1}$ interacts with NbROS1L. a BiFC analysis of the interaction of $\beta C 1$ with NbROS1L. Scale bars, $50 \mu \mathrm{m}$. $\mathbf{b}$ BiFC analysis of the interactions of $\beta C 1$ with the N-terminal region of NbROS1L (nNbROS1L) and the C-terminal region of NbROS1L (cNbROS1L). Scale bars, $50 \mu \mathrm{m}$. Schematic representation of NbROS1L protein structure is shown above. c Co-immunoprecipitation analysis of the interactions of $\beta C 1$ with nNbROS1L and cNbROS1L. YFP was used as a negative control. d BiFC analysis of the interaction between $\beta C 1 \mathrm{V17A}$ and NbROS1L. Scale bars, $50 \mu \mathrm{m}$. e Co-immunoprecipitation analysis of the interaction between $\beta C 1 \mathrm{V17A}$ and $\mathrm{nNbROS1L}$. YFP was used as a negative control. Images in a-e are representative of three independent experiments. Raw data for $\mathbf{a}, \mathbf{b}$ and $\mathbf{d}$ and uncropped blots for $\mathbf{c}$ and $\mathbf{e}$ are provided in the source data.

if $\beta \mathrm{C} 1$ can interact with Arabidopsis DNA glycosylases. BiFC results revealed that $\beta \mathrm{C} 1$ could interact with DME (Supplementary Fig. 7a). Similar to what was observed for NbROS1L, we found that the N-terminal region of DME and the Val in position 17 of $\beta C 1$ were required for the interaction (Fig. $4 \mathrm{a}$ and Supplementary Fig. $7 \mathrm{~b}-\mathrm{e})$. We next determined whether the $\beta C 1-D M E$ interaction promotes viral virulence. With this aim, we generated transgenic Arabidopsis expressing $\beta \mathrm{C} 1$ or $\beta C 1^{\mathrm{V} 17 \mathrm{~A}}$, and then inoculated these plants with the Arabidopsis-infecting geminivirus beet severe curly top virus (BSCTV) (Supplementary Fig. 8a). Wild-type (Col-0) plants developed mild curly top symptoms after BSCTV infection, while the $\beta \mathrm{C} 1$-expressing plants developed dramatically more severe symptoms (Fig. 4b and Supplementary Fig. 8b). These symptoms were largely ameliorated when $\beta \mathrm{C} 1^{\mathrm{V} 17 \mathrm{~A}}$ was expressed instead (Fig. 4b and Supplementary Fig. 8b). Consistent with this, a high level of BSCTV DNA was accumulated in the $\beta C 1$-expressing plants, while viral accumulation was decreased in the $\beta C 1^{\mathrm{V} 17 \mathrm{~A}}$-expressing plants (Fig. $4 \mathrm{c}$, d and Supplementary Fig. 8c). The high accumulation of BSCTV DNA and the development of severe symptoms in $\beta \mathrm{C} 1$ expressing plants were associated with hypomethylation of BSCTV DNA, which was restored to a great extent in $\beta \mathrm{C} 11^{\mathrm{V} 17 \mathrm{~A}}$ expressing plants (Fig. 4e). These results suggest that the $\beta \mathrm{C} 1$ DME interaction is important for BSCTV DNA hypomethylation and virulence in Arabidopsis. 
a
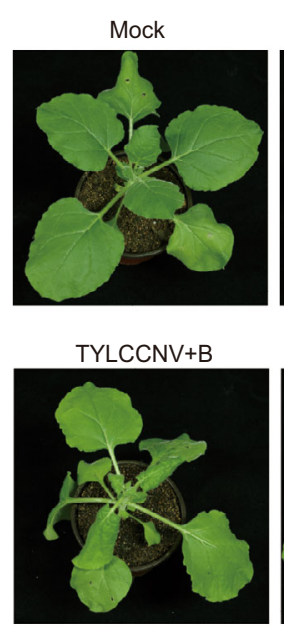

b
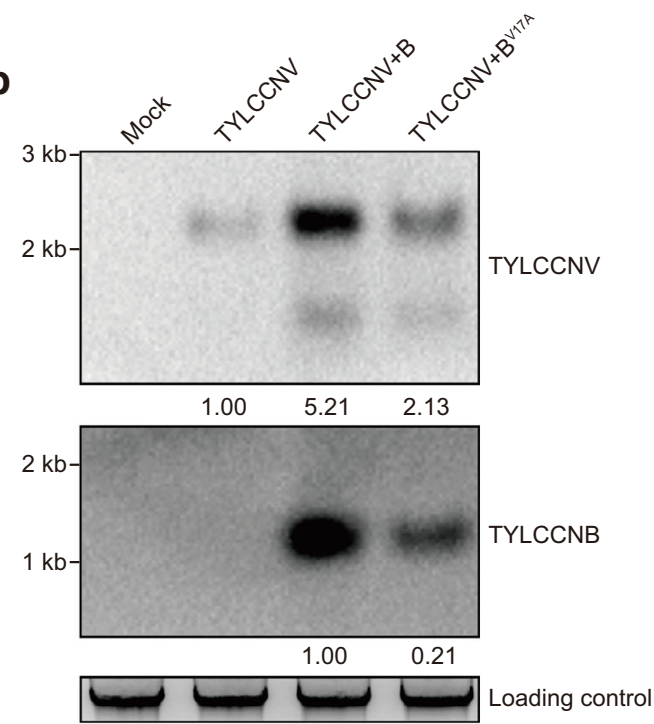

C

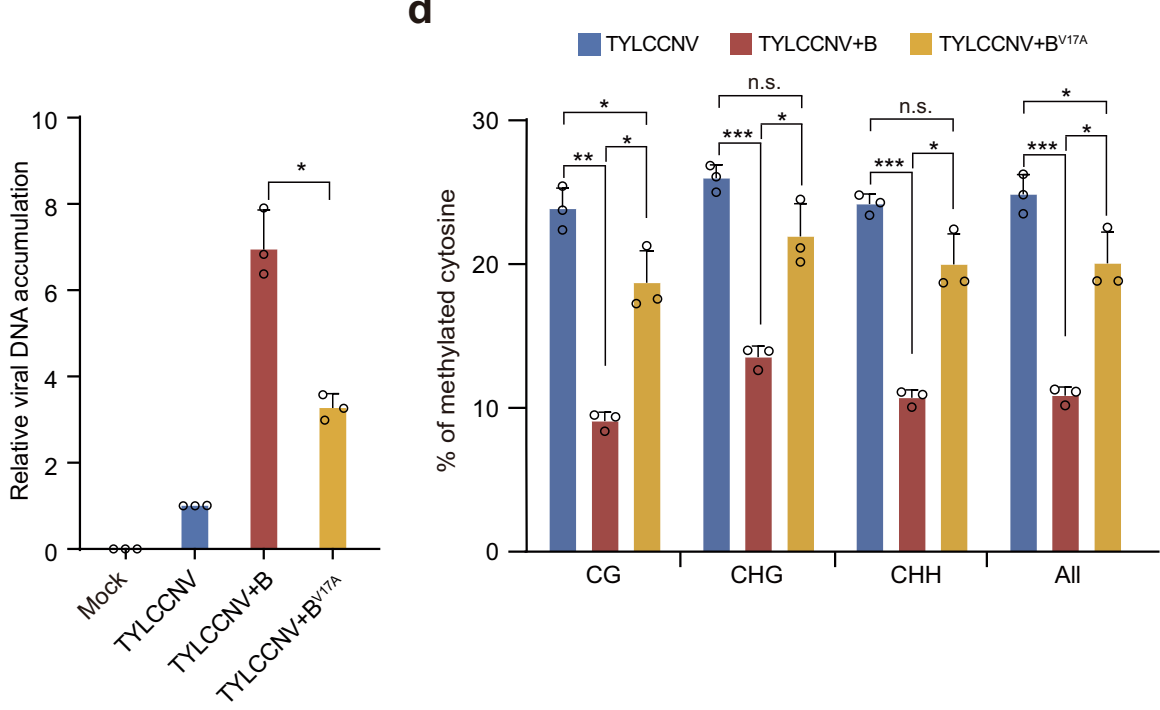

Fig. 3 The $\boldsymbol{\beta}$ C1-NbROS1L interaction is important for TYLCCNV+B virulence and viral DNA hypomethylation. a Symptoms of N. benthamiana plants mock-inoculated or inoculated with TYLCCNV, TYLCCNV+B or TYLCCNV+BV17A at 10 dpi. Scale bar, $2 \mathrm{~cm}$. b Accumulation of TYLCCNV and TYLCCNB in the leaves of indicated plants at $10 \mathrm{dpi}$ as determined by Southern blot. Total DNA was stained with EB as loading control. c Accumulation of TYLCCNV in the leaves of indicated plants at $10 \mathrm{dpi}$ as determined by qPCR. The coat protein gene of TYLCCNV was amplified. The N. benthamiana $25 S$ nuclear rRNA gene (Nb25SrRNA) was used as an internal control. Values are means \pm SD ( $n=3$ independent experiments). Statistical significance was determined using two-tailed Student's $t$ test; ${ }^{*} p<0.05$. d Percentage of methylated cytosines in the intergenic region (IR) of TYLCCNV in the leaves of indicated plants at 10 dpi as determined by bisulfite sequencing. Values are means \pm SD ( $n=3$ independent experiments). Statistical significance was determined using twotailed Student's $t$ test; ${ }^{\star} p<0.05,{ }^{\star \star} p<0.01,{ }^{\star \star \star} p<0.001$, ns not significant. Uncropped pictures, blots and gels for $\mathbf{a}$ and $\mathbf{b}$, raw data and $p$ values for $\mathbf{c}$ and d are provided in the source data.

$\beta C 1$ promotes DME activity in vitro and in vivo. DME has both DNA glycosylase and apyrimidinic lyase activities, which mediate the removal of $5 \mathrm{mC}$ from double-stranded DNA and the cleavage of the DNA backbone at the abasic site to produce $\beta$ - and $\beta, \delta$-elimination products, respectively ${ }^{40,41}$. Because the $\beta \mathrm{C} 1$-DME interaction promotes viral DNA hypomethylation, we wondered whether the interaction can directly enhance the activity of DME. To test this, recombinant DME, GST- $\beta C 1$, and GST- $\beta C 1^{\mathrm{V} 17 \mathrm{~A}}$ were expressed and purified (Supplementary Fig. 9a). A 5'-fluorescein-labeled oligonucleotide substrate containing $5 \mathrm{mC}$ was incubated with DME plus varying amounts of GST, GST- $\beta \mathrm{C} 1$, or GST- $\beta \mathrm{C} 1^{\mathrm{V} 17 \mathrm{~A}} \cdot \beta$ - and $\beta$, $\delta$-elimination products were yielded when the substrate was incubated with DME. The amount of products was increased when GST- $\beta$ C1 was added; however, this was abolished when GST- $\beta C 1$ was replaced with GST- $\beta C 1$ V17A (Fig. $5 \mathrm{a}, \mathrm{b}$ and Supplementary Fig. 9b). These results suggest that $\beta C 1$ can directly enhance the activity of DME through protein-protein interaction.

Given that DME activity was enhanced by $\beta C 1$ in vitro, we asked whether this would also occur in vivo. To test this possibility, we generated transgenic $N$. benthamiana plants overexpressing DME (Supplementary Fig. 10a) and inoculated these plants with TYLCCNV alone, TYLCCNV+B, or TYLCCNV+BV17A. We found that DME-overexpressing plants, like wild-type plants, did not show any symptoms when inoculated with TYLCCNV alone 
a

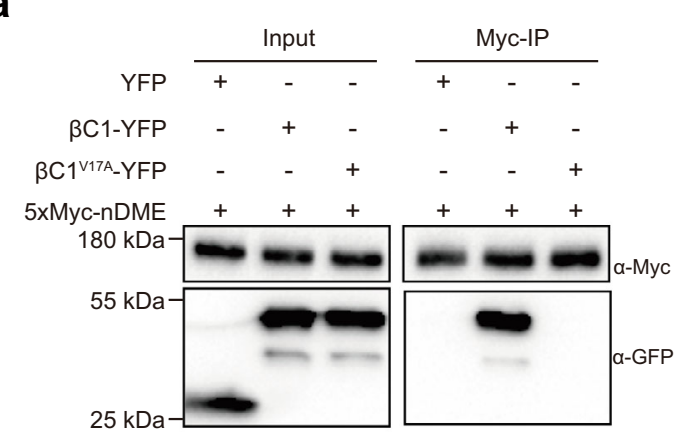

C
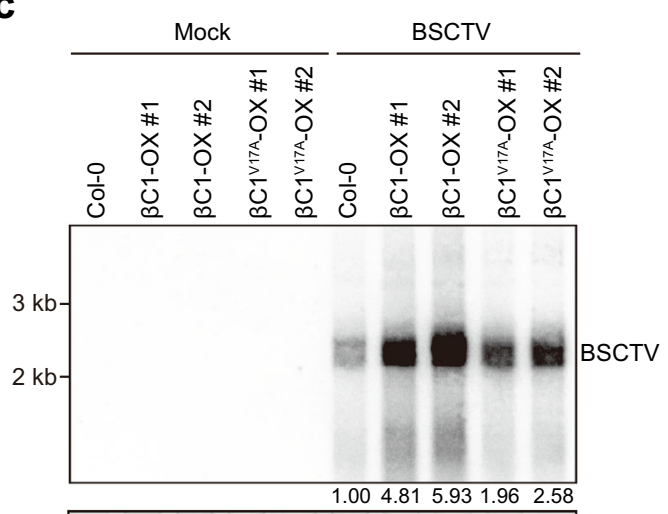

$\square \smile \smile-\square-$ Loading control b
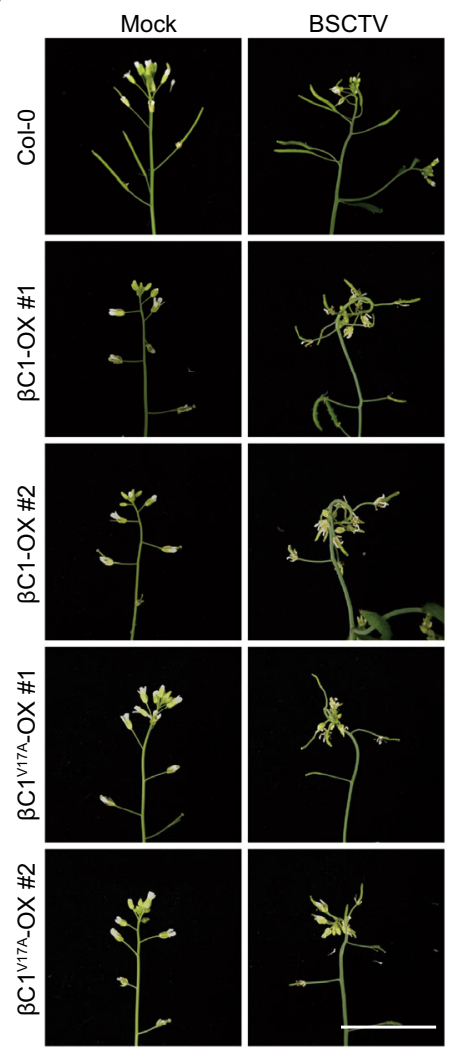

d

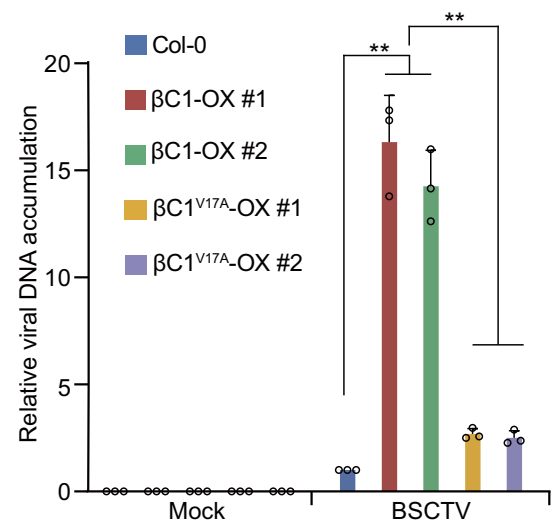

e

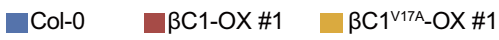

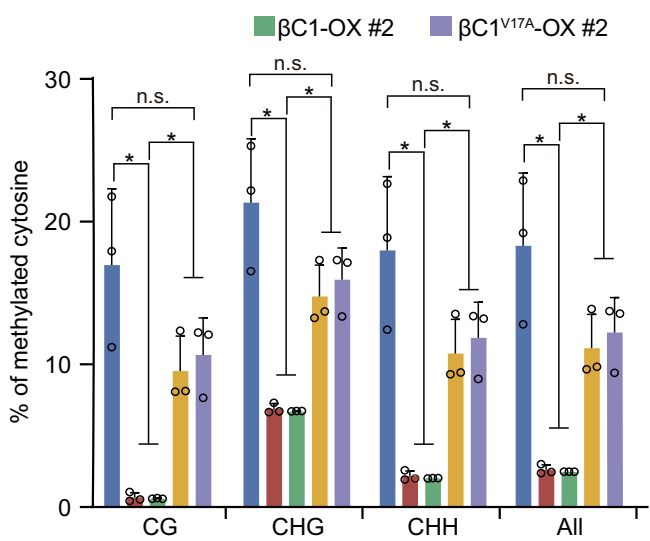

Fig. 4 The $\boldsymbol{\beta}$ C1-DME interaction promotes BSCTV virulence in Arabidopsis. a Co-immunoprecipitation analysis of the interactions of $\beta C 1$ or $\beta C 1 \mathrm{~V} 17 \mathrm{~A}$ with the N-terminal region of DME (nDME). YFP was used as a negative control. Results are representative of three independent experiments. $\mathbf{b}$ Symptoms of Col-0, $\beta C 1$-expressing lines and $\beta C 1$ V17A-expressing lines inoculated with BSCTV at $10 \mathrm{dpi}$. Scale bars, $2 \mathrm{~cm}$. $\mathbf{c}$ Accumulation of BSCTV in the indicated plants at $10 \mathrm{dpi}$ as determined by Southern blot. Total DNA was stained with EB as loading control. d Accumulation of BSCTV in the indicated plants at 10 $\mathrm{dpi}$ as determined by qPCR. The coat protein gene of BSCTV was amplified. The Arabidopsis 255 nuclear rRNA gene (At25SrRNA) was used as an internal control. Values are means \pm SD $\left(n=3\right.$ independent experiments). Statistical significance was determined using two-tailed Student's $t$ test; ${ }^{* \star} p<0.01$. e Percentage of methylated cytosines in the intergenic region (IR) of BSCTV in the indicated plants at 10 dpi as determined by bisulfite sequencing. Values are means \pm SD ( $n=3$ independent experiments). Statistical significance was determined using two-tailed Student's $t$ test; ${ }^{*} p<0.05$, ns not significant. Uncropped pictures, blots and gels for $\mathbf{a}, \mathbf{b}$ and $\mathbf{c}$, raw data and $p$ values for $\mathbf{d}$ and $\mathbf{e}$ are provided in the source data.

(Fig. 5c and Supplementary Fig. 10b). However, they developed more severe symptoms than wild-type plants when inoculated with TYLCCNV $+\mathrm{B}$, an effect that was abolished when the plants were inoculated with TYLCCNV $+\mathrm{B}^{\mathrm{V} 17 \mathrm{~A}}$ (Fig. $5 \mathrm{c}$ and Supplementary Fig. 10b). Consistent with this, DME-overexpressing plants inoculated with TYLCCNV $+\mathrm{B}$ had lower levels of viral DNA methylation and accumulated higher levels of TYLCCNV/B, compared to those inoculated with TYLCCNV+BV17A (Fig. 5d-f and Supplementary Fig. 10c). These data suggest that overexpression of DME enhances TYLCCNV infection by further decreasing the level of viral DNA methylation, and that the interaction between $\beta \mathrm{C} 1$ and $\mathrm{DME}$ is required for this process. 
a

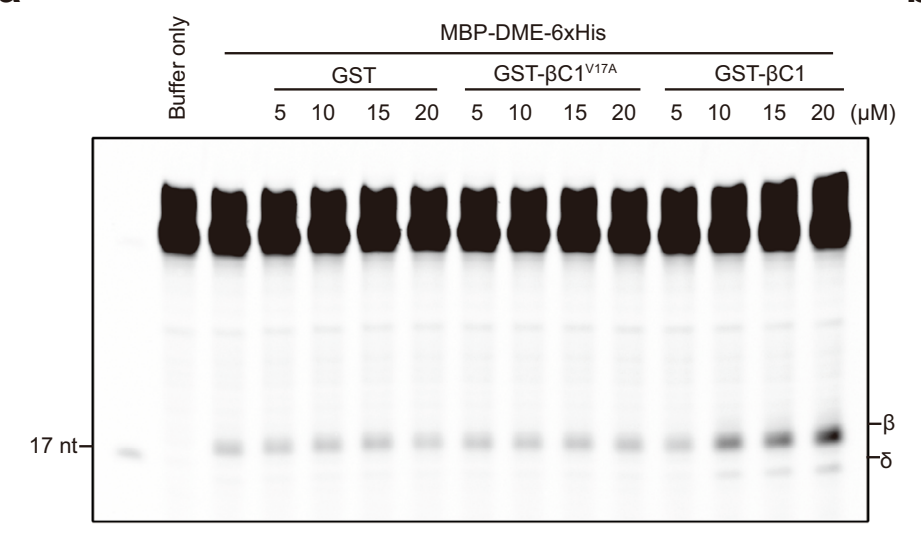

C

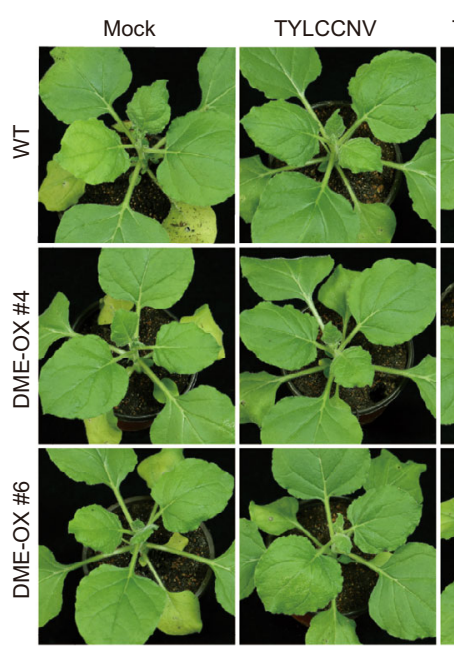

e

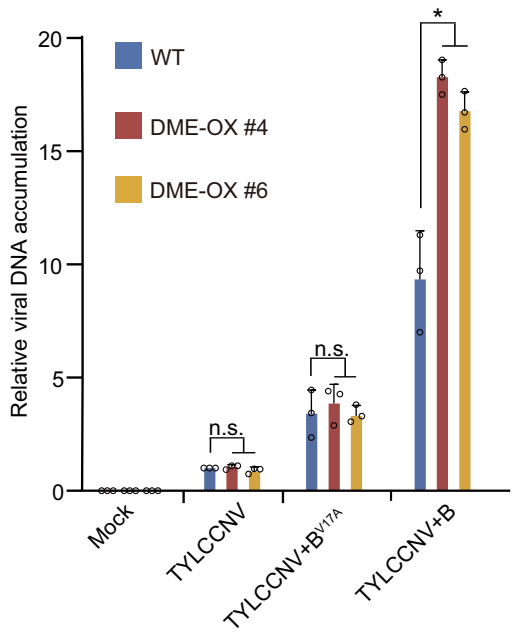

f

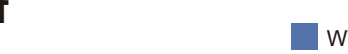

b
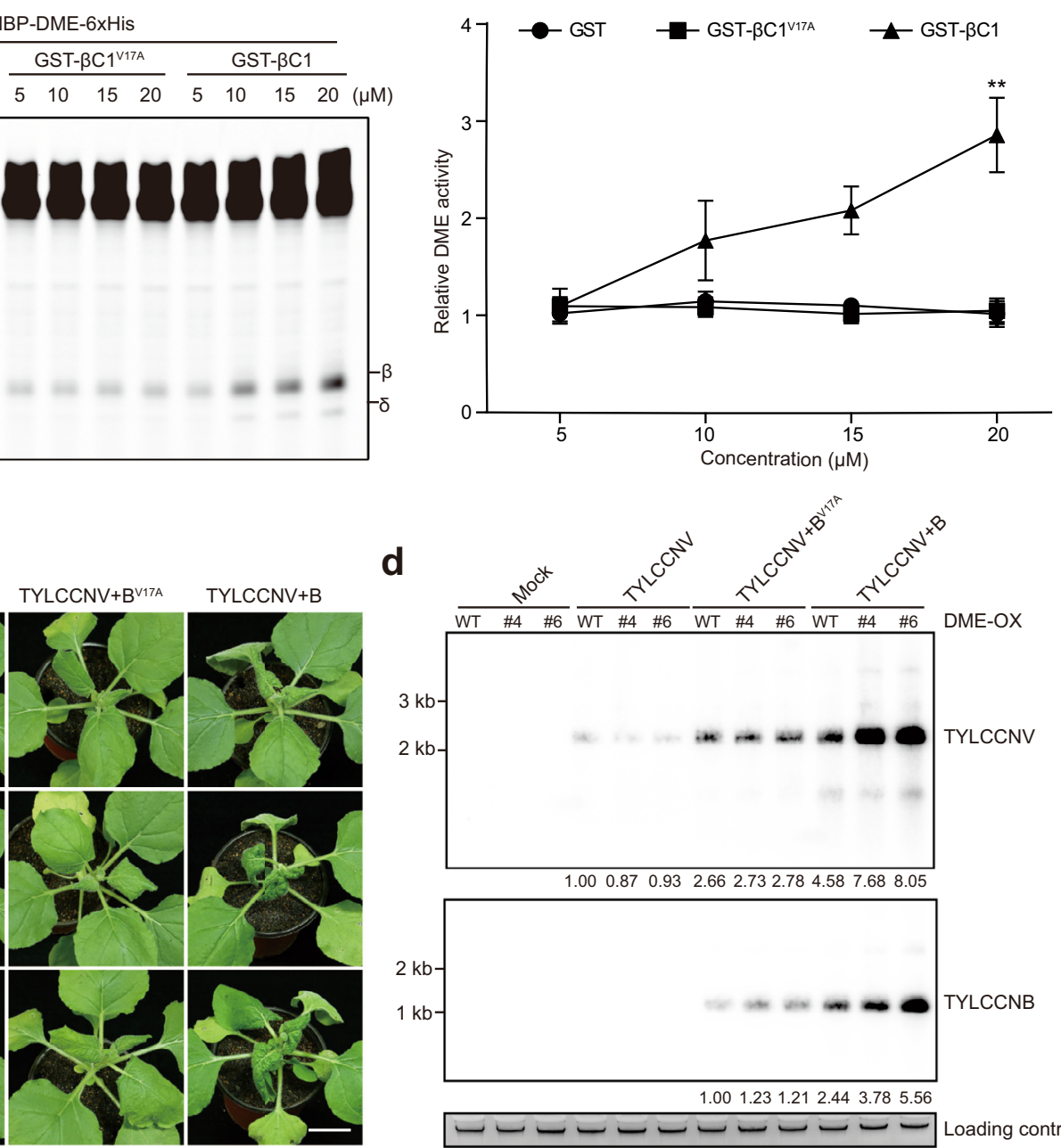

d

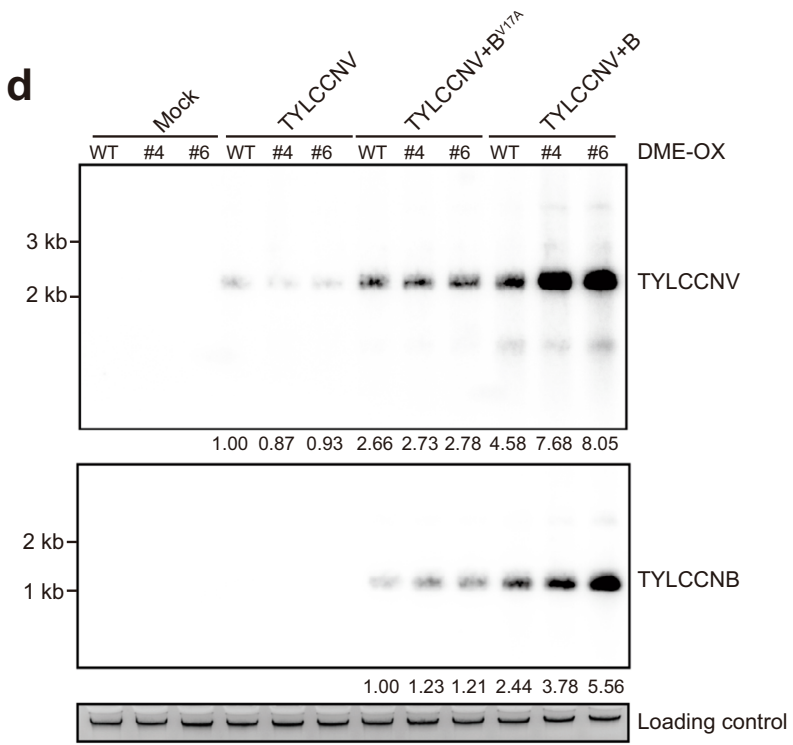

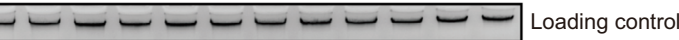

WT DME-OX\#4 DME-OX\#6

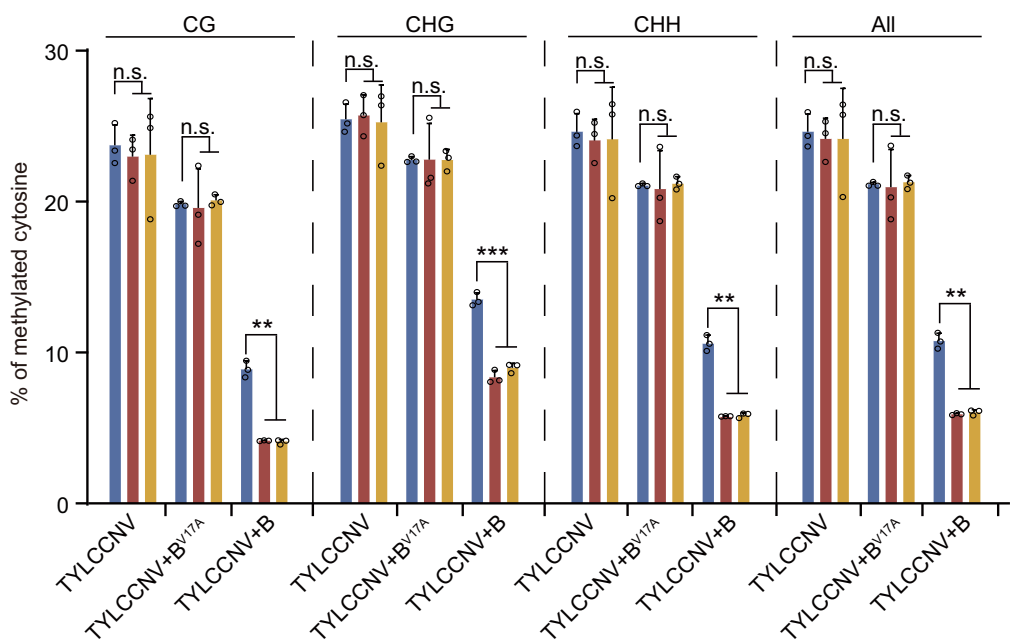

\section{Discussion}

Active DNA demethylation plays an important role in shaping genomic DNA methylation patterns and regulating transcription of many endogenous loci $^{1}$. In this study, we show that active DNA demethylation targets DNA of TYLCCNV and its betasatellite TYLCCNB to promote their virulence. $\beta C 1$ regulates the activity or targeting of active DNA demethylation for suppression of viral DNA methylation and enhancement of viral virulence.

$D M E$ was originally identified by mutations that cause maternal effects on seed viability ${ }^{11}$, and has been thought to be expressed and function specifically in reproductive tissues during gametogenesis for gene and transposon activation ${ }^{11,13,17}$. However, $D M E$ has been detected to be constitutively expressed 
Fig. $5 \boldsymbol{\beta C} 1$ promotes DME activity in vitro and in vivo. a In vitro $5 \mathrm{mC}$ excision activity of DME protein. Double-stranded oligonucleotide substrate (one strand methylated) was incubated with DME and varying amounts of GST, GST- $\beta$ C1 or GST- $\beta$ C1V17A . 17-nucleotide size marker and $\beta$ - and $\delta$-elimination products are indicated. $\mathbf{b}$ Quantification of relative DME activity. Values are means \pm SD ( $n=3$ independent experiments). Statistical significance was determined using two-tailed Student's $t$ test; ${ }^{*} p<0.01$. c Symptoms of wild-type and DME-overexpressing $N$. benthamiana lines mock-inoculated or inoculated with TYLCCNV, TYLCCNV+B or TYLCCNV+BV17A at $10 \mathrm{dpi}$. Scale bar, $2 \mathrm{~cm}$. d Accumulation of TYLCCNV and TYLCCNB in the leaves of indicated plants at $10 \mathrm{dpi}$ as determined by Southern blot. Total DNA was stained with EB as loading control. e Accumulation of TYLCCNV in the leaves of indicated plants at $10 \mathrm{dpi}$ as determined by qPCR. The coat protein gene of TYLCCNV was amplified. The N. benthamiana $25 S$ nuclear rRNA gene (Nb25SrRNA) was used as an internal control. Values are means \pm SD ( $n=3$ independent experiments). Statistical significance was determined using twotailed Student's $t$ test; ${ }^{*} p<0.05$, ns not significant. $\mathbf{f}$ Percentage of methylated cytosines in the intergenic region (IR) of TYLCCNV in the leaves of indicated plants at $10 \mathrm{dpi}$ as determined by bisulfite sequencing. Values are means \pm SD ( $n=3$ independent experiments). Statistical significance was determined using two-tailed Student's $t$ test; ${ }^{\star \star} p<0.01,{ }^{\star \star \star} p<0.001$, ns not significant. Uncropped pictures, blots and gels for $\mathbf{a}$, $\mathbf{c}$ and $\mathbf{d}$, raw data and $p$ values for $\mathbf{b}$, e and $\mathbf{f}$ are provided in the source data.

in vegetative tissues by microarray, RNA-sequencing, RT-PCR and GUS reporter analyses ${ }^{12,42-45}$. DME also functions in vegetative tissues. Knockdown of DME expression leads to DNA hypermethylation at hundreds of genomic regions, which eventually leads to downregulated expression of dozens of genes under normal growth conditions ${ }^{45}$ and compromised activation of defense-related genes and increased plant susceptibility to infection when the plants are invaded by bacterial or fungal pathogens ${ }^{4,45}$. Our data suggest that DME can be activated by a viral suppressor protein to reduce DNA methylation level of the viruses in plant leaves. Our findings provide evidence that DME expression and function extend beyond reproductive tissues in Arabidopsis. In M. truncatula, DME is expressed in the root nodules, an organ formed in legumes through symbiotic interaction with nitrogen-fixing rhizobia, and DME expression is required for activation of many nodule differentiation-associated genes and normal development of nodules ${ }^{46}$. It will be interesting to investigate whether DME also targets genes of rhizobia and how its activity is regulated.

We showed that TYLCCNB is required for active DNA demethylation activity on viral DNA. We further found that $\beta \mathrm{C} 1$ interacts with DME and enhances the DNA demethylation activity of DME in vitro (Figs. $4 \mathrm{a}$ and $5 \mathrm{a}, \mathrm{b}$ ), suggesting that $\beta \mathrm{C} 1$ may increase NbROS1L and DME activity on viral DNA. This could be achieved through inducing structural or conformational changes. However, we cannot at this point exclude the possibility that $\beta \mathrm{C} 1$ may facilitate NbROS1L or DME targeting to the viral genome. Supporting this possibility, we found that loss of $N b R O S 1 L$ or overexpression of $D M E$ has no effect on viral DNA methylation level, viral replication, and virulence, in the absence of TYLCCNB or $\beta C 1$ (Figs. 1 and 5). It is possible that access of $\mathrm{NbROS1L/DME}$ to the viral DNA requires assistance from another protein. Since $\beta \mathrm{C} 1$ has been shown to bind both single-stranded and double-stranded DNA in vitro, albeit lacking size or sequence specificity ${ }^{47}$, it could provide such function. Furthermore, $\beta \mathrm{C} 1$ can substitute for the DNA B component of tomato leaf curl New Delhi virus (ToLCNDV), a bipartite begomovirus, to help the DNA A component of ToLCNDV move and sustain systemic infection of tomato plants ${ }^{48}$, indicating that $\beta \mathrm{C} 1$ likely has DNA-binding ability in vivo. Nonetheless, it is possible that active DNA demethylation could also target plant endogenous genes to promote vial virulence.

We have previously found that $\beta \mathrm{C} 1$ also interacts with and inactivates SAHH to reduce viral DNA methylation ${ }^{22}$. The V17A mutation of $\beta C 1$ disrupts the interaction between $\beta C 1$ and NbROS1L or DME but does not affect the interaction between $\beta \mathrm{C} 1$ and $\mathrm{SAHH}$, allowing us to uncouple the effects caused by $\beta C 1$-mediated activation of NbROS1L or DME and those caused by $\beta \mathrm{C} 1$-mediated suppression of SAHH. We found that TYLCCNV DNA methylation level is lower when $\beta C 1$ carries the V17A mutation (Fig. 3d) or when NbDMLs are silenced compared to that in TYLCCNV-inoculated control (Fig. 1d).
Similarly, BSCTV DNA methylation level is lower in $\beta C 1^{\text {V17A }}$ OX plants than in Col-0 (Fig. 4e). These results suggest that $\beta \mathrm{C} 1$-mediated suppression of SAHH activity also contributes to $\beta C 1$-mediated suppression of DNA methylation. Thus, DNA viruses have evolved to both suppress DNA methylation and boost active DNA demethylation as counter-defense strategies.

\section{Methods}

Plant materials and growth conditions. The $35 S:: R F P-H 2 B$ transgenic $N$. ben thamiana line was previously described ${ }^{49}$. Other plant materials, including $35 S:: 5 \times M y c-D M E N$. benthamiana transgenic line and $35 S:: 3 \times$ Flag- $\beta C 1$ and $35 S:: 3 \times$ Flag- $\beta C 1^{V 17 A}$ Arabidopsis transgenic lines, were generated in this study. $N$. benthamiana plants were grown in a controlled growth chamber at $25^{\circ} \mathrm{C}$ under a $16 \mathrm{~h}$ light $/ 8 \mathrm{~h}$ dark photoperiod and Arabidopsis plants were grown in a growth room under long photoperiod conditions $\left(16 \mathrm{~h}\right.$ light, $22^{\circ} \mathrm{C} / 8 \mathrm{~h}$ dark, $\left.18^{\circ} \mathrm{C}\right)$.

Cloning. cDNAs of NbROS1, NbROS1L, NbDML3, NbDML4, NbDML5 and NbDML6 were PCR-amplified, cloned into the pLB vector (TIANGEN, VT205) and sequenced. Three cDNA fragments of NbROS1, NbDML3, and NbDML4 were fused by overlap PCR and the fusion product was cloned into the pTRV2 vector ${ }^{50}$, generating the TRV-based VIGS vector pTRV2-NbDMLs for knockdown of $\mathrm{NbDMLs}$. For BiFC, the coding sequence of $\beta \mathrm{C} 1$ and cDNAs of NbROS1, NbROS1L, NbDML3, NbDML4, NbDML5, NbDML6, ROS1, DML2, DML3 and $D M E$ were PCR-amplified and cloned into p2YN and p2YC. For mapping the regions of NbROS1L and DME that mediate the interactions with $\beta \mathrm{C} 1$, cDNAs corresponding to the N-terminal and C-terminal regions of NbROS1L and DME were PCR-amplified and cloned into p2YN and p2YC. For mapping the region and residue of $\beta \mathrm{C} 1$ that mediate the interactions with NbROS1L and DME, the coding sequence of $\beta C 1$ was PCR-amplified and cloned into the $\mathrm{pLB}$ vector. The construct was used to generate all the truncated and mutant forms of $\beta \mathrm{C} 1$ using the $\mathrm{KOD}$ Plus-Mutagenesis Kit (TOYOBO, SMK-101). For co-immunoprecipitation, the coding sequences of $\beta \mathrm{C} 1$ and $\beta \mathrm{C} 1^{\mathrm{V} 17 \mathrm{~A}}$ were PCR-amplified and cloned into pCambia1300-35S-YFP and pCambia1300-35S-3 $\times$ Flag to generate 35S- $\beta$ C1-YFP, $35 \mathrm{~S}-\beta \mathrm{C} 1^{\mathrm{V} 17 \mathrm{~A}}-\mathrm{YFP}, 35 \mathrm{~S}-3 \times$ Flag- $\beta \mathrm{C} 1$, and $35 \mathrm{~S}-3 \times$ Flag- $\beta \mathrm{C1} 1^{\mathrm{V} 17 \mathrm{~A}}$ constructs. CDNAs corresponding to the N-terminal and C-terminal regions of NbROS1L were PCR-amplified and cloned into pCambia1300-35S-5 $\times$ Myc, generating 35S$5 \times$ Myc-nNbROS1L and 35S-5 $\times$ Myc-cNbROS1L constructs. cDNAs corresponding to $D M E$ and the N-terminal regions of $D M E$ were PCR-amplified and cloned into pCambia1300-35S-5 $\times$ Myc, generating 35S-5 $\times$ Myc-DME and 35S$5 \times$ Myc-nDME constructs. For the evaluation of TYLCCNV $+\mathrm{B}^{\mathrm{V} 17 \mathrm{~A}}$ virulence, the sequence of TYLCCNB was cloned into the $\mathrm{PLB}$ vector and the construct was used to introduce the $\beta C 1^{\mathrm{V} 17 \mathrm{~A}}$ point mutation, generating $\mathrm{pLB}-\mathrm{TYLCCNB}{ }^{\mathrm{V} 17 \mathrm{~A}}$. The sequence of TYLCCNB ${ }^{V 17 A}$ was PCR-amplified and cloned into pBinPLUS to generate pBinPLUS-TYLCCNB ${ }^{\text {V17A }}$ using the ClonExpress II One Step Cloning kit (Vazyme, C112-02). pLB-TYLCCNB ${ }^{V 17 A}$ was digested with KpnI and EcoRI and the product was cloned into pBinPLUS-TYLCCNB ${ }^{\mathrm{V} 17 \mathrm{~A}}$, generating pBinPLUS$2 \mathrm{TYLCCNB}{ }^{\mathrm{V} 17 \mathrm{~A}}$. For the expression of recombinant proteins in E. coli, the coding sequences of $\beta C 1$ and $\beta C 1^{\text {V17A }}$ were PCR-amplified and cloned into the pGEX4T-3 vector and the coding sequence of DME were PCR-amplified and cloned into the pET11-6 $\times$ His-MBP vector ${ }^{51}$.

Agroinfitration and virus inoculation. All binary plasmids were individually transformed into Agrobacterium tumefaciens strain EHA105. The transformants were cultured in liquid LB with appropriate antibiotics, collected by centrifugation and resuspended in the infiltration buffer $\left(10 \mathrm{mM} \mathrm{MgCl}_{2}, 10 \mathrm{mM} \mathrm{MES} \mathrm{pH} \mathrm{5.6,}\right.$ $100 \mathrm{mM}$ acetosyringone). The suspensions were placed in dark for $2 \mathrm{~h}$ at room temperature before infiltration.

For TYLCCNV inoculation following VIGS, A. tumefaciens cultures carrying pCambia1300, pTRV1 plus pTRV2-GUS (TRV-GUS) or pTRV1 plus pTRV2-

NbDMLs (TRV-NbDMLs) at an OD600 $=0.2$ were inoculated into N. benthamiana 
plants at the eight-leaf stage. One week later, A. tumefaciens cultures harboring pBinPLUS (mock) or infectious clones of TYLCCNV or TYLCCNV plus TYLCCNB $($ TYLCCNV+B) at an OD600 $=1.0$ were inoculated into pCambia1300-, TRV-GUS- or TRV-NbDMLs-infiltrated plants. For other TYLCCNV inoculation, $N$. benthamiana plants at the eight-leaf stage were directly agroinoculated with infectious clones of TYLCCNV, TYLCCNV+B or TYLCCNV $+\mathrm{B}^{\mathrm{V} 17 \mathrm{~A}}$. For BSCTV inoculation, 4-week-old Arabidopsis plants were inoculated during bolting period and the bolts were cut at their base. The cut was applied with A. tumefaciens cultures carrying pCambia1300 (mock) or infectious clones of BSCTV and then insect pins were used to puncture the cut multiple times ${ }^{27}$. Symmetrically infected leaves were harvested at 10 days post inoculation.

RNA extraction and RT-qPCR. RNA was isolated using an Eastep Super Total RNA Extraction kit (Promega, LS1040) and $1 \mu \mathrm{g}$ of total RNA was reversely transcribed by M-MLV reverse transcriptase (Invitrogen, 28025013). qPCR was conducted using SYBR Premix EX Taq (TaKaRa, RR420A). NbACT2 was used an internal control. Primer sequences are listed in Supplementary Table 1.

DNA extraction, Southern blot analysis, and qPCR. Total DNA was extracted from infected plant leaves using Plant Genomic DNA Kit (TIANGEN, DP305). For detection of viral DNA accumulation by Southern blot, $1 \mu \mathrm{g}$ of total DNA was loaded onto $1.0 \%$ agarose gels and separated by electrophoresis. Agarose gels were denatured with denaturing buffer $(0.5 \mathrm{M} \mathrm{NaOH}, 1.5 \mathrm{M} \mathrm{NaCl})$ for $40 \mathrm{~min}$ and

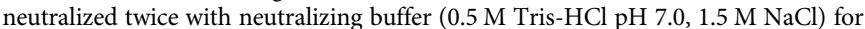
$20 \mathrm{~min}$. After denaturation and neutralization, total DNA was transferred to Hybond $\mathrm{N}^{+}$nylon membranes (GE Healthcare, RPN303B). TYLCCNV+B and BSCTV DNA probes were labeled with $\left[\alpha^{-32} \mathrm{P}\right]$ dCTP using Random Primer DNA Labeling Kit Ver. 2 (TaKaRa, 6045) or with digoxigenin (DIG) using DIG High Prime DNA labeling and detection starter kit II (Roche, 11585614910). Membranes were hybridized at $65^{\circ} \mathrm{C}$ overnight and washed three times with $1 \times$ SSC, $0.1 \%$ SDS at $65^{\circ} \mathrm{C}$ for $15 \mathrm{~min}$. The radioactive signal was detected by Personal Molecular Imager (Bio-Rad) and the signal obtained with the DIG-labeled probes was detected by Image Lab (Bio-Rad). For detection of viral DNA accumulation by qPCR, the coat protein genes of TYLCCNV and BSCTV were amplified as described previously ${ }^{52}$. Primer sequences for generating the probes are listed in Supplementary Table 1

DNA bisulfite sequencing analysis. Total DNA (500 ng) was subjected to bisulfite treatment using EZ DNA Methylation Gold ${ }^{\mathrm{TM}}$ Kit (Zymo Research, D5005), according to the manufacturer's instructions. The bisulfite-treated DNA was used as templates for amplification of the IR region of TYLCCNV or BSCTV. Primer sequences are listed in Supplementary Table 1. The products were purified with AMPure XP beads (Beckman, A63880) and the purified DNA products were PCRamplified and the adapters were added using GXL DNA polymerase (Takara, R050Q) and primer F (5'-AATGATACGGCGACCACCGAGATCTACAC-IndexTCGTCGGCAGCGTC- $3^{\prime}$ ) and primer R (5'-CAAGCAGAAGACGGCATACGA GAT-Index-GTCTCGTGGGCTCGG) $)^{53}$. The final products were purified with AMPure XP beads for sequencing on an Illumina HiSeqX-Ten platform by Annoroad Gene Technology (Beijing). PCR-duplicated reads were removed and the unique reads with read counts above 5 were retained for cytosine methylation analysis using Kismeth (http://katahdin.mssm.edu/kismeth/revpage.pl).

BiFC assay. Equal volumes of $A$. tumefaciens cultures at an $\mathrm{OD} 600=1.0$. were mixed prior to infiltration. Leaves of 4 -week-old $35 S:: R F P-H 2 B$ transgenic $N$. benthamiana line were infiltrated with A. tumefaciens cultures carrying pairs of BiFC constructs. Epidermal cells of the assayed leaves were examined by confocal laser scanning microscopy 980 (Zeiss, GER) $48 \mathrm{~h}$ post infiltration. For confocal imaging, the excitation wavelength for YFP was set at $514 \mathrm{~nm}$ and the emission was captured at $565-585 \mathrm{~nm}$, and the excitation wavelength for RFP was set at $543 \mathrm{~nm}$ and the emission was captured at $590-630 \mathrm{~nm}$. RFP-H2B signals were used to mark the nucleus.

Co-immunoprecipitation. Four-week-old $N$. benthamiana leaves were infiltrated with $A$. tumefaciens cultures carrying the pCambia 1300 constructs. Forty-eight hours post infiltration, the leaves were collected and ground in liquid nitrogen. Total proteins were extracted from $2 \mathrm{~g}$ of ground powder in $4 \mathrm{ml}$ of IP buffer $(50 \mathrm{mM}$ Tris- $\mathrm{HCl}$ pH 7.5, $150 \mathrm{mM} \mathrm{NaCl}, 5 \mathrm{mM} \mathrm{MgCl}$, 2 mM EDTA, $0.5 \%$ Triton X-100, 5\% glycerol, $5 \mathrm{mM}$ DTT, $1 \mathrm{mM}$ PMSF, and 1 Protease Inhibitor Cocktail tablet (Roche, 4693116001)). The extract was centrifuged three times at $20,000 \times g$ for $10 \mathrm{~min}$ each time at $4{ }^{\circ} \mathrm{C}$ and the supernatant was collected. Twenty-five microliters of anti-c-mycagarose affinity gel (Sigma-Aldrich, A7470) or GBP beads (homemade) were added to the supernatant and incubated at $4{ }^{\circ} \mathrm{C}$ for $2 \mathrm{~h}$ with rotation. After incubation, the beads were washed three times with IP buffer at $4{ }^{\circ} \mathrm{C}$. Finally, $50 \mu$ l of $2 \times$ SDS loading buffer were added to the sample for western blot analyses.

Western blot analysis. Proteins were separated by SDS-PAGE and transferred to nitrocellulose membranes (GE Healthcare, 10600003). Membranes were incubated with primary antibodies and secondary antibodies sequentially. Primary antibodies we used include anti-GFP (Roche, 11814460001, 1:5000 dilution), anti-c-myc
(Roche, 11667203001, 1:2000 dilution), anti-Flag M2 (Sigma, F1804, 1:5000 dilution), anti-HA (Roche, 11666606001, 1:5000 dilution), anti-actin (Sangon, D191048, 1:5000 dilution) and anti- $\alpha$-tubulin (Sigma, T5168, 1:5000 dilution). Horseradish peroxidase-conjugated goat anti-mouse IgG (Sigma, A4416, 1:5000 dilution) was used as the secondary antibody. ECL prime western blot detection reagent (GE Healthcare, RPN2232) was added to the membranes for chemiluminescence detection using Image Lab (Bio-Rad).

Expression and purification of recombinant proteins. The constructs expressing $\beta \mathrm{C} 1, \beta \mathrm{C} 1^{\mathrm{V} 17 \mathrm{~A}}$ and DME were transformed into E. coli BL21 (DE3) cells and transformants were grown at $37^{\circ} \mathrm{C}$ until the $\mathrm{OD}_{600}$ reached 0.6. Protein expression was induced by the addition of $0.5 \mathrm{mM}$ isopropyl $\beta$-D-1-thiogalactopyranoside at $18{ }^{\circ} \mathrm{C}$ for $16 \mathrm{~h}$. Cells were harvested and resuspended in lysis buffer $(40 \mathrm{mM}$ Tris$\mathrm{HCl} \mathrm{pH} \mathrm{8.0,500} \mathrm{mM} \mathrm{NaCl,} 10 \%$ glycerol and $1 \mathrm{mM}$ PMSF). The suspension was lysed by sonication and centrifuged at $20,000 \mathrm{~g}$ for $1 \mathrm{~h}$ at $4^{\circ} \mathrm{C}$. For purification of His-tagged proteins, the supernatant was loaded onto a column packed with $\mathrm{Ni}$ NTA. After washing with washing buffer $(40 \mathrm{mM}$ Tris- $\mathrm{HCl} \mathrm{pH} 8.0,500 \mathrm{mM} \mathrm{NaCl}$, $20 \mathrm{mM}$ imidazole), proteins were eluted with elution buffer ( $40 \mathrm{mM}$ Tris- $\mathrm{HCl} \mathrm{pH}$ $8.0,500 \mathrm{mM} \mathrm{NaCl}$, and $500 \mathrm{mM}$ imidazole). For purification of GST-tagged proteins, the supernatant was loaded onto a column packed with glutathione sepharose 4B agarose beads (GE Healthcare, 17-0756-01). The beads were washed with washing buffer $(40 \mathrm{mM}$ Tris- $\mathrm{HCl} \mathrm{pH} 8.0,500 \mathrm{mM} \mathrm{NaCl})$ and proteins were eluted with elution buffer (40 mM Tris- $\mathrm{HCl} \mathrm{pH} 8.0,500 \mathrm{mM} \mathrm{NaCl}$ and $20 \mathrm{mM}$ glutathione reduced). For purification of both His-tagged and GST-tagged proteins, gel filtration was performed on Superdex 200 increase size exclusion columns (GE Healthcare, 28-9909-44) with gel filtration buffer ( $40 \mathrm{mM}$ Tris- $\mathrm{HCl} \mathrm{pH} 8.0$, $150 \mathrm{mM} \mathrm{NaCl}$ and $1 \mathrm{mM}$ DTT) and peak fractions were collected.

DME activity assay. DME activity assay was performed as described ${ }^{54}$. A pair of Cy5 end-labeled oligonucleotides (one strand methylated) were synthesized and annealed, generating double-stranded oligonucleotide substrate. The substrate was incubated with $0.5 \mu \mathrm{M}$ DME plus varying amounts of GST, GST- $\beta C 1$ or GST$\beta C 1^{\mathrm{V} 17 \mathrm{~A}}$ in a $15-\mu \mathrm{l}$ reaction containing $40 \mathrm{mM}$ Tris- $\mathrm{HCl} \mathrm{pH} 8.0,0.1 \mathrm{M} \mathrm{KCl}$, $0.1 \mathrm{mM}$ EDTA, $0.5 \mathrm{mM}$ DTT, and $200 \mu \mathrm{g} / \mathrm{ml} \mathrm{BSA}$ at $37^{\circ} \mathrm{C}$ for $30 \mathrm{~min}$. The reaction was terminated by the addition of $15 \mu \mathrm{l}$ of loading buffer ( $95 \%$ formamide, $0.025 \%$ bromophenol blue, $0.025 \%$ SDS, $18 \mathrm{mM}$ EDTA). The sample was heated at $95^{\circ} \mathrm{C}$ for $10 \mathrm{~min}$, and then chilled on ice. The sample was loaded onto $15 \%$ denaturing polyacrylamide gels and reaction products were separated by electrophoresis. Cy5 signal was detected using Typhoon (GE Healthcare) and quantified using ImageJ.

Reporting summary. Further information on research design is available in the Nature Research Reporting Summary linked to this article.

\section{Data availability}

Bisulfite sequencing dataset generated in this study can be found in the NCBI Gene Expression Omnibus under accession number GSE188968. A reporting summary for this article is available as a Supplementary Information file. Source data are provided with this paper.

Received: 23 June 2021; Accepted: 12 January 2022; Published online: 31 January 2022

\section{References}

1. Zhang, H., Lang, Z. \& Zhu, J. K. Dynamics and function of DNA methylation in plants. Nat. Rev. Mol. Cell Biol. 19, 489-506 (2018).

2. Lister, R. et al. Highly integrated single-base resolution maps of the epigenome in. Arabidopsis. Cell 133, 523-536 (2008).

3. Zhang, X. Y. et al. Genome-wide high-resolution mapping and functional analysis of DNA methylation in. Arabidopsis. Cell 126, 1189-1201 (2006).

4. Stroud, H., Greenberg, M. V., Feng, S., Bernatavichute, Y. V. \& Jacobsen, S. E. Comprehensive analysis of silencing mutants reveals complex regulation of the Arabidopsis methylome. Cell 152, 352-364 (2013).

5. Matzke, M. A. \& Mosher, R. A. RNA-directed DNA methylation: an epigenetic pathway of increasing complexity. Nat. Rev. Genet 15, 394-408 (2014).

6. Kankel, M. W. et al. Arabidopsis MET1 cytosine methyltransferase mutants. Genetics 163, 1109-1122 (2003).

7. Lindroth, A. M. et al. Requirement of CHROMOMETHYLASE3 for maintenance of CpXpG methylation. Science 292, 2077-2080 (2001).

8. Zemach, A. et al. The Arabidopsis nucleosome remodeler DDM1 allows DNA methyltransferases to access H1-containing heterochromatin. Cell 153, 193-205 (2013)

9. Roje, S. S-Adenosyl-L-methionine: beyond the universal methyl group donor Phytochemistry 67, 1686-1698 (2006) 
10. Gong, Z. H. et al. ROS1, a repressor of transcriptional gene silencing in Arabidopsis, encodes a DNA glycosylase/lyase. Cell 111, 803-814 (2002).

11. Choi, Y. et al. DEMETER, a DNA glycosylase domain protein, is required for endosperm gene imprinting and seed viability in Arabidopsis. Cell 110, 33-42 (2002).

12. Ortega-Galisteo, A. P., Morales-Ruiz, T., Ariza, R. R. \& Roldan-Arjona, T. Arabidopsis DEMETER-LIKE proteins DML2 and DML3 are required for appropriate distribution of DNA methylation marks. Plant Mol. Biol. 67, 671-681 (2008).

13. Schoft, V. K. et al. Function of the DEMETER DNA glycosylase in the Arabidopsis thaliana male gametophyte. Proc. Natl Acad. Sci. USA 108, 8042-8047 (2011).

14. Qian, W. et al. A histone acetyltransferase regulates active DNA demethylation in Arabidopsis. Science 336, 1445-1448 (2012)

15. Lin, W. et al. Active DNA demethylation regulates tracheary element differentiation in Arabidopsis. Sci. Adv. 6, eaaz2963 (2020).

16. Yamamuro, C. et al. Overproduction of stomatal lineage cells in Arabidopsis mutants defective in active DNA demethylation. Nat. Commun. 5, 4062 (2014).

17. Khouider, S. et al. Male fertility in Arabidopsis requires active DNA demethylation of genes that control pollen tube function. Nat. Commun. 12, 410 (2021).

18. Hsieh, T. F. et al. Genome-wide demethylation of Arabidopsis endosperm. Science 324, 1451-1454 (2009).

19. Walker, P. J. et al. Changes to virus taxonomy and to the International Code of Virus Classification and nomenclature ratified by the International Committee on Taxonomy of Viruses (2021). Arch. Virol. 166, 2633-2648 (2021).

20. Cui, X., Tao, X., Xie, Y., Fauquet, C. M. \& Zhou, X. A DNAbeta associated with tomato yellow leaf curl China virus is required for symptom induction. J. Virol. 78, 13966-13974 (2004).

21. $\mathrm{Hu}, \mathrm{T}$. et al. betaCl protein encoded in geminivirus satellite concertedly targets MKK2 and MPK4 to counter host defense. PLoS Pathog. 15, e1007728 (2019).

22. Yang, X. et al. Suppression of methylation-mediated transcriptional gene silencing by betaC1-SAHH protein interaction during geminivirusbetasatellite infection. PLoS Pathog. 7, e1002329 (2011)

23. Li, F., Huang, C., Li, Z. \& Zhou, X. Suppression of RNA silencing by a plant DNA virus satellite requires a host calmodulin-like protein to repress RDR6 expression. PLoS Pathog. 10, e1003921 (2014).

24. Yang, J. Y. et al. betaC1, the pathogenicity factor of TYLCCNV, interacts with AS1 to alter leaf development and suppress selective jasmonic acid responses. Genes Dev. 22, 2564-2577 (2008).

25. Jia, Q. et al. CLCuMuB betaCl subverts ubiquitination by interacting with NbSKP1s to enhance geminivirus infection in Nicotiana benthamiana. PLoS Pathog. 12, e1005668 (2016).

26. Zhang, T. et al. Begomovirus-whitefly mutualism is achieved through repression of plant defences by a virus pathogenicity factor. Mol. Ecol. 21, 1294-1304 (2012).

27. Raja, P., Sanville, B. C., Buchmann, R. C. \& Bisaro, D. M. Viral genome methylation as an epigenetic defense against geminiviruses. J. Virol. 82, 8997-9007 (2008).

28. Piedra-Aguilera, A. et al. Integrated single-base resolution maps of transcriptome, sRNAome and methylome of tomato yellow leaf curl virus (TYLCV) in tomato. Sci. Rep. 9, 2863 (2019).

29. Deuschle, K., Kepp, G. \& Jeske, H. Differential methylation of the circular DNA in geminiviral minichromosomes. Virology 499, 243-258 (2016).

30. Ermak, G., Paszkowski, U., Wohlmuth, M., Mittelsten Scheid, O. \& Paszkowski, J. Cytosine methylation inhibits replication of African cassava mosaic virus by two distinct mechanisms. Nucleic Acids Res. 21, 3445-3450 (1993).

31. Brough, C. L. et al. DNA methylation inhibits propagation of tomato golden mosaic virus DNA in transfected protoplasts. Plant Mol. Biol. 18, 703-712 (1992).

32. Wang, Y. et al. Geminiviral V2 protein suppresses transcriptional gene silencing through interaction with AGO4. J. Virol. 93, e01675-18 (2019).

33. Wang, L. et al. A virus-encoded protein suppresses methylation of the viral genome through its interaction with AGO4 in the Cajal body. Elife 9, e55542 (2020).

34. Mei, Y., Wang, Y., Li, F. \& Zhou, X. The C4 protein encoded by tomato leaf curl Yunnan virus reverses transcriptional gene silencing by interacting with NbDRM2 and impairing its DNA-binding ability. PLoS Pathog. 16, e1008829 (2020).

35. Rodriguez-Negrete, E. et al. Geminivirus Rep protein interferes with the plant DNA methylation machinery and suppresses transcriptional gene silencing. $N$. Phytol. 199, 464-475 (2013).

36. Wang, B., Yang, X., Wang, Y., Xie, Y. \& Zhou, X. Tomato yellow leaf curl Virus V2 interacts with host histone deacetylase 6 to suppress methylation-mediated transcriptional gene silencing in plants. J. Virol. 92, e00036-18 (2018).

37. Wang, H., Hao, L., Shung, C. Y., Sunter, G. \& Bisaro, D. M. Adenosine kinase is inactivated by geminivirus AL2 and L2 proteins. Plant Cell 15, 3020-3032 (2003).

38. Ismayil, A. et al. Cotton Leaf Curl Multan virus C4 protein suppresses both transcriptional and post-transcriptional gene silencing by interacting with SAM synthetase. PLoS Pathog. 14, e1007282 (2018).

39. Zhang, Z. et al. BSCTV C2 attenuates the degradation of SAMDC1 to suppress DNA methylation-mediated gene silencing in Arabidopsis. Plant Cell 23, 273-288 (2011).

40. Gehring, M. et al. DEMETER DNA glycosylase establishes MEDEA polycomb gene self-imprinting by allele-specific demethylation. Cell 124, 495-506 (2006).

41. Morales-Ruiz, T. et al. DEMETER and REPRESSOR OF SILENCING 1 encode 5-methylcytosine DNA glycosylases. Proc. Natl Acad. Sci. USA 103, 6853-6858 (2006).

42. Schmid, M. et al. A gene expression map of Arabidopsis thaliana development. Nat. Genet. 37, 501-506 (2005).

43. Klepikova, A. V., Kasianov, A. S., Gerasimov, E. S., Logacheva, M. D. \& Penin, A. A. A high resolution map of the Arabidopsis thaliana developmental transcriptome based on RNA-seq profiling. Plant J. 88, 1058-1070 (2016).

44. Schumann, U. et al. DEMETER plays a role in DNA demethylation and disease response in somatic tissues of Arabidopsis. Epigenetics 14, 1074-1087 (2019).

45. Zeng, W. et al. Roles of DEMETER in regulating DNA methylation in vegetative tissues and pathogen resistance. J. Integr. Plant Biol. 63, 691-706 (2020).

46. Satge, C. et al. Reprogramming of DNA methylation is critical for nodule development in Medicago truncatula. Nat. Plants 2, 16166 (2016).

47. Cui, X., Li, G., Wang, D., Hu, D. \& Zhou, X. A Begomovirus DNAbetaencoded protein binds DNA, functions as a suppressor of RNA silencing, and targets the cell nucleus. J. Virol. 79, 10764-10775 (2005).

48. Saeed, M., Zafar, Y., Randles, J. W. \& Rezaian, M. A. A monopartite begomovirus-associated DNA beta satellite substitutes for the DNA B of a bipartite begomovirus to permit systemic infection. J. Gen. Virol. $\mathbf{8 8}$, 2881-2889 (2007)

49. Martin, K. et al. Transient expression in Nicotiana benthamiana fluorescent marker lines provides enhanced definition of protein localization, movement and interactions in planta. Plant J. 59, 150-162 (2009).

50. Dinesh-Kumar, S. P., Anandalakshmi, R., Marathe, R., Schiff, M. \& Liu, Y. Virus-induced gene silencing. Methods Mol. Biol. 236, 287-294 (2003).

51. Xie, D. et al. Phase separation of SERRATE drives dicing body assembly and promotes miRNA processing in Arabidopsis. Nat. Cell Biol. 23, 32-39 (2021).

52. Zhong, X. et al. Mimic phosphorylation of a betaC1 protein encoded by TYLCCNB impairs its functions as a viral suppressor of RNA silencing and a symptom determinant. J. Virol. 91, e00300-17 (2017).

53. Jiang, P. et al. 21-nt phasiRNAs direct target mRNA cleavage in rice male germ cells. Nat. Commun. 11, 5191 (2020).

54. Mok, Y. G. et al. Domain structure of the DEMETER 5-methylcytosine DNA glycosylase. Proc. Natl Acad. Sci. USA 107, 19225-19230 (2010).

\section{Acknowledgements}

This work is funded by grants from National Natural Science Foundation of China (31720103914, 31930089 and 31788103).

\section{Author contributions}

X.Z. and Y.Q. designed the experiments; X.G. performed the research; X.G., C.L., Y.Q., and X.Z. analyzed the data and wrote the paper.

\section{Competing interests}

The authors declare no competing interests.

\section{Additional information}

Supplementary information The online version contains supplementary material available at https://doi.org/10.1038/s41467-022-28262-3.

Correspondence and requests for materials should be addressed to Yijun Qi or Xueping Zhou.

Peer review information Nature Communications thanks the anonymous reviewer(s) for their contribution to the peer review of this work. Peer reviewer reports are available.

Reprints and permission information is available at http://www.nature.com/reprints

Publisher's note Springer Nature remains neutral with regard to jurisdictional claims in published maps and institutional affiliations. 
(c) (i) Open Access This article is licensed under a Creative Commons Attribution 4.0 International License, which permits use, sharing, adaptation, distribution and reproduction in any medium or format, as long as you give appropriate credit to the original author(s) and the source, provide a link to the Creative Commons license, and indicate if changes were made. The images or other third party material in this article are included in the article's Creative Commons license, unless indicated otherwise in a credit line to the material. If material is not included in the article's Creative Commons license and your intended use is not permitted by statutory regulation or exceeds the permitted use, you will need to obtain permission directly from the copyright holder. To view a copy of this license, visit http://creativecommons.org/ licenses/by/4.0/.

(C) The Author(s) 2022 